\title{
Prenatal Development of Cat Retinogeniculate Axon Arbors in the Absence of Binocular Interactions
}

\author{
David W. Sretavan and Carla J. Shatz \\ Department of Neurobiology, Stanford University School of Medicine, Stanford, California 94305
}

\begin{abstract}
During prenatal development of the cat's retinogeniculate projection, inputs from the ganglion cell axons of the two eyes are initially intermixed with each other within the lateral geniculate nucleus (LGN). As development proceeds, the inputs sort out to give rise to the eye-specific layers characteristic of the adult. During this sorting out process, individual axons undergo a stereotyped sequence of morphological changes that ultimately produce the characteristic pattern of arborization in which axon arbors are restricted in extent only to those layers of the LGN appropriate for the eye of origin (Sretavan and Shatz, 1984, 1986). Here, we examine whether binocular interactions between retinal ganglion cell axons from the two eyes are required for the formation of this restricted pattern of terminal arborization.
\end{abstract}

To examine this question, one eye was removed at embryonic day 23 (E23), when ganglion cell axons have not yet reached the optic chiasm, and the ganglion cell axons from the remaining eye were allowed to develop in the complete absence of binocular interactions. At E59, when segregation into eye-specific layers is normally almost complete, the retinogeniculate projection from the remaining eye was then examined both by anterograde transport following intraocular injections of ${ }^{3} \mathrm{H}$-leucine and by the in vitro filling of individual ganglion cell axons with HRP. Results from the intraocular injections showed that in the absence of one eye, the remaining eye is still capable of forming both ipsilateral and contralateral optic tracts; however, the projection was distributed diffusely throughout each LGN, rather than being confined to normal eye-specific territories.

When individual HRP-filled axons were reconstructed and examined, it was remarkable to find that the pattern of terminal arborization was virtually indistinguishable from normal axons. As usual, arbors were restricted to the distal portion of each axon trunk, and measurements showed that the total linear length of axon contributing to each arbor was within the normal range (enucleated, $2310 \pm 920 \mu \mathrm{m}$; normal, $2520 \pm 810 \mu \mathrm{m}$ ). Furthermore, the terminal arborizations of axons appeared to be organized into a series of tiers within the LGN in a pattern surprisingly similar to the pattern of eye-specific layers normally present by E59. Also unchanged was the normally occurring loss of axons from the remaining optic nerve: Counts at E59 showed that about $2.3 \times 10^{5}$ axons were present in enucleated animals as compared to $2.5 \times 10^{5}$ axons in controls.

Received June 24, 1985; revised Sept. 12, 1985; accepted Sept. 23, 1985.

We wish to thank Drs. E. I. Knudsen, U. J. McMahan, P. Rakic, and R. W. Williams for their insightful comments on the manuscript; Terold Chun, Marla Luskin, Sandra Shotwell, and Mark Siegel for their assistance with surgery; and Mark Nakamura for help in measuring axons. Thanks also to Mark Siegel for photographic assistance and Cecele Thomas for expert secretarial assistance. This research was supported by NIH Grant EY 02858, NSF Grant BNS 8317228, the McKnight Foundation and the March of Dimes.

Correspondence should be addressed to Drs. Sretavan and Shatz, Department of Neurobiology, Stanford University School of Medicine, Stanford, CA 94305.

Copyright (C) 1986 Society for Neuroscience $0270-6474 / 86 / 040990-14 \$ 02.00 / 0$
Finally, examination of a retinal whole-mount of the remaining eye at $\mathbf{E 5 9}$ indicated that the normal central to peripheral gradient of ganglion cell density was also present.

These observations indicate that although binocular interactions are necessary for some aspects of the development of the retinogeniculate projection, a number of important developmental events can still occur in the absence of binocular interactions. These include the normally occurring reduction in axon number in the optic nerve and the restriction of ganglion cell terminal arbors within the LGN. Thus, interactions that occur between ganglion cells intrinsic to one eye may be equally important in the formation of the retinogeniculate projection.

In the adult mammalian visual system, each lateral geniculate nucleus (LGN) receives inputs from retinal ganglion cells of both eyes, and these inputs are segregated into a series of eye-specific layers. However, during development, inputs from the two eyes are initially intermixed with each other within the LGN, and the adult segregated pattern only emerges subsequently (cats: Shatz, 1983; ferrets: Card-Linden et al., 1981; hamsters: Frost et al., 1979; So et al., 1978, 1984; monkeys: Rakic, 1977; opossums: Cavalcante and Rocha-Miranda, 1978; possums: Sanderson ct al., 1982; rats: Bunt et al., 1983). We have studied the morphological correlates of this developmental process at the level of individual retinal ganglion cell axons by examining the sequential change in branching pattern of retinogeniculate axons filled with HRP during fetal development in the cat (Sretavan and Shatz, 1984, 1986). Our results show that during the initial period of intermixing of eye inputs, axons along their entire course through the LGN are studded with short side branches, some of which are located in territory that is destined to belong exclusively to the other eye. As the eye-specific layers emerge, axons simultaneously retract selected side branches from inappropriate territory and elaborate a terminal arbor within LGN territory appropriate to their eye of axon origin.

In view of these observations, it seemed essential to learn more about the mechanisms responsible for producing the branching pattern of individual retinogeniculate axons. One possibility is that binocular competitive interactions between the axons from the two eyes (perhaps via the elaboration and retraction of side branches) produce the restricted branching pattern of mature retinogeniculate axons. Recent evidence supporting binocular competition as a mechanism has come from experiments in which one eye is removed during development at a time when retinal projections from the two eyes are intermixed within the LGN. The global pattern of projection from the remaining eye is then examined at some later developmental age or in adulthood by intraocular injections of anterograde tracers (Chalupa and Williams, 1984; Rakic, 1981; So et al., 1984; for review, see Shatz and Sretavan, 1986). Results from these studies have consistently demonstrated that the inputs from the surviving eye, instead of being restricted only to parts 
of the nucleus appropriate to that eye, have now spread throughout. Thus, early eye removal can prevent the development of the adult segregated pattern of eye input, suggesting that this aspect of the normal development of connections between retina and LGN depends on the presence of afferents from both eyes.

The major question we wish to address here is whether binocular interactions are also required to produce the normal restricted terminal arborization pattern of individual retinogeniculate axons. To answer this question, we have modified somewhat the approach used previously. In order to examine the development of individual retinogeniculate axons in the complete absence of binocular interactions, we removed one eye in cat fetuses at embryonic day 23 (E23), a time when ganglion cell axons have not yet reached the optic chiasm (Williams et al., 1986; J. Silver, M. Kliot, and C. J. Shatz, unpublished observations). The resulting pattern of the retinogeniculate projection and the morphological appearance of individual retinal ganglion cell axons from the remaining eye were then studied at E59, when normally the segregation of eye input is essentially complete (Sretavan and Shatz, 1986). As expected, our results based on the intraocular injection of anterograde tracers show that the remaining eye projects throughout both the contralateral and the ipsilateral LGN. However, when individual retinogeniculate axons were visualized by filling them with HRP in vitro, it was remarkable to find that all had restricted patterns of terminal arborization virtually identical to those seen in normal animals, indicating that binocular interactions are not strictly necessary for this particular aspect of morphological development. A brief report of these findings has been presented (Sretavan et al., 1984).

\section{Materials and Methods}

In order to produce a retinogeniculate system innervated exclusively by afferents from one eye, we performed monocular enucleations on cat fetuses at E23 of the $65 \mathrm{~d}$ gestation period. At E23, retinal axons have just grown out of the globe into the optic nerve, and none have yet reached the optic chiasm (Williams et al., 1986; J. Silver, M. Kliot, and C. J. Shatz, unpublished observations). After surgery, fetuses were allowed to develop further in utero until E59 and then the retinogeniculate projection from the remaining eye was studied to compare it with the projection in normal fetuses of the same age. By E59 individual retinogeniculate afferents in normal animals have already developed restricted terminal arbors (Sretavan and Shatz, 1984, 1986) and the adultlike pattern of separate and nonoverlapping layers is already present (Shatz, 1983). All experiments reported here were performed on normally pigmented cat fetuses taken from timed-pregnant mothers bred for 24 or $48 \mathrm{hr}$. In $48 \mathrm{hr}$ breedings, the second day was counted as the first day of gestation (E1).

\section{Surgery}

Cesarian sections were performed with animals under general anesthesia using a mixture of halothane/nitrous oxide/oxygen. Expired $\mathrm{CO}_{2}$ was monitored and maintained at $3.5-4 \%$, and dextrose (5\%) Ringer's solution was given intravenously throughout the entire surgical procedure. Terbutaline sulfate (Brethine, Geigy) was also given intravenously in $0.1-0.2 \mathrm{mg}$ boluses when necessary to conirol uterine contractions. Further details of the surgical procedure can be found in Shatz (1983).

\section{Fetal enucleations}

At E23, each of multiple uterine sacs is about $2-2.5 \mathrm{~cm}$ long, with the fctus containcd within cach sac about $1-1.5 \mathrm{~cm}$ in crown-rump length. To expose a fetus, an incision was made through the uterine musculature and the placenta longitudinally along the middle or at one end of each sac. When possible, only the head of the fetus was exposed through the incision. Great care was taken not to incise the chorionic and amniotic membranes, except immediately overlying the eye intended for removal. A hand-held electric cautery (Storz) was used to puncture these membranes and destroy the eye. A cautery tip size of about a millimeter was selected, since at this age the eye is also approximately a millimeter in diameter. A second, less reliable, method was to surgically excise the eye by microdissection. After enucleation, the fetuses were gently rein- serted deep within the uterine sac and the overlying incisions closed. Because of the fragility of fetuses at such early stages of in utero development, only about $20 \%$ of the operated animals survived into late gestation.

\section{Intraocular injections of tritiated leucine}

After monocular enucleation, the fetuses were allowed to develop further in utero until E58. Each fetus then received a single intraocular injection of $250 \mu \mathrm{Ci}^{3} \mathrm{H}$-leucine (New England Nuclear, NET 135H: specific activity, $40-60 \mathrm{Ci} / \mathrm{mmol}$ ) in $25 \mu \mathrm{l}$ of $0.9 \%$ saline along the temporal ciliary margin to label the entire retinogeniculate projection from the remaining eye (see Shatz, 1983, for complete details). After a survival of $24 \mathrm{hr}$, the injected fetuses were delivered by cesarian section at E59 and prepared either for in vitro labeling of retinogeniculate axons (see below) or processed for autoradiography.

For autoradiography, the fetuses were perfused intracardially with $4 \%$ paraformaldehyde in $0.1 \mathrm{M}$ phosphate buffer ( $\mathrm{pH} 7.4)$. After postfixation and embedding, frozen sections $(20 \mu \mathrm{m})$ were cut in the horizontal plane through the LGN and portions of the optic tract. Every fifth section was processed for autoradiography using NTB-2 liquid emulsion (Shatz, 1983). An additional set of sections was stained with cresyl violet.

\section{In vitro labeling of retinogeniculate afferents}

The main objective of this study was to examine the branching pattern of individual retinogeniculate axons that developed in the absence of interactions with afferents from the other eye. To do this, we used an in vitro method to fill fetal optic tract axons with HRP (Sretavan and Shatz, 1984, 1986). This method involves the dissection and removal of part of the diencephalon, including the optic tract and the LGN from the cranium. Small deposits of HRP are then made into the tract and the entire preparation is placed in a tissue slice chamber for 4-6 hr. During this incubation period, the preparation is continuously superfused with oxygenated mammalian Ringer's solution supplemented with $5 \%$ glucose and maintained at $32-34^{\circ} \mathrm{C}$.

For histological analysis, the fetal preparations were immersion-fixed in a mixture of $1 \%$ paraformaldehyde, $1.25 \%$ glutaraldehyde in $0.1 \mathrm{M}$ phosphate buffer ( $\mathrm{pH} 7.4)$. After overnight fixation (15-18 hr), $100 \mu \mathrm{m}$ sections through the LGN were cut in the horizontal plane on a vibratome. Free-floating sections were reacted for HRP histochemistry using a modification of the diaminobenzidine and $\mathrm{CoCl}_{2}$ intensification method of Adams (1981). HRP-filled afferents were examined using a $63 \times$ Zeiss planapo objective (oil, N.A. 1.4), and the terminal arbors of retinogeniculate axons were reconstructed from multiple sections with a camera lucida. In this study, a total of 25 retinogeniculate axons filled with HRP were completely reconstructed. Details of the in vitro method for labeling fetal axons and the evaluation of the technique have been presented previously (Sretavan and Shatz, 1986). This method reliably allows the filling and detailed examination of retinogeniculate axons throughout the entire period of development between E38 and birth.

Since each fetus studied in vitro had received an intraocular injection of ${ }^{3} \mathrm{H}$-leucine $24 \mathrm{hr}$ earlier, the entire retinogeniculate projection was also labeled. After the reconstruction of HRP-labeled afferents, the retinal projections were examined in the same material by applying a ${ }^{3} \mathrm{H}$ sensitive film (LKB ultrofilm) directly against each tissue section. The LKB film was exposed for $10 \mathrm{~d}$ and then developed (Sretavan and Shatz, 1986). In the same in vitro preparations, portions of the optic tract below the level of the LGN were saved and the radioactive label within the optic tract examined after processing for autoradiography. To do this, portions of the diencephalon containing the optic tracts were reimmersed in $4 \%$ paraformaldehyde in $0.1 \mathrm{M}$ phosphate buffer with $20 \%$ sucrose. Frozen sections $(20 \mu \mathrm{m})$ were then taken and processed for liquid emulsion autoradiography as described above.

\section{Electron microscopic analysis of optic nerve}

The number of axons in the remaining optic nerves of monocularly enucleated animals and in the optic nerves of control animals was determined at E59 using quantitative electron microscopic analysis. To prepare the optic nerves for electron microscopy, the control animals (not enucleated) were perfused intracardially with a mixture of $2 \%$ paraformaldehyde, $2.5 \%$ glutaraldehyde, and $0.2 \%$ acrolein with $4 \mathrm{mM} \mathrm{CaCl}$ in $0.1 \mathrm{M}$ sodium cacodylate buffer (pH 7.35). In two monocularly enucleated animals, immediately after the optic tracts and LGNs had been removed for the in vitro labeling of retinal afferents, the optic nerve was promptly immersion-fixed in the same electron-microscopic fixative for 


\section{CONTRALATERAL IPSILATERAL}
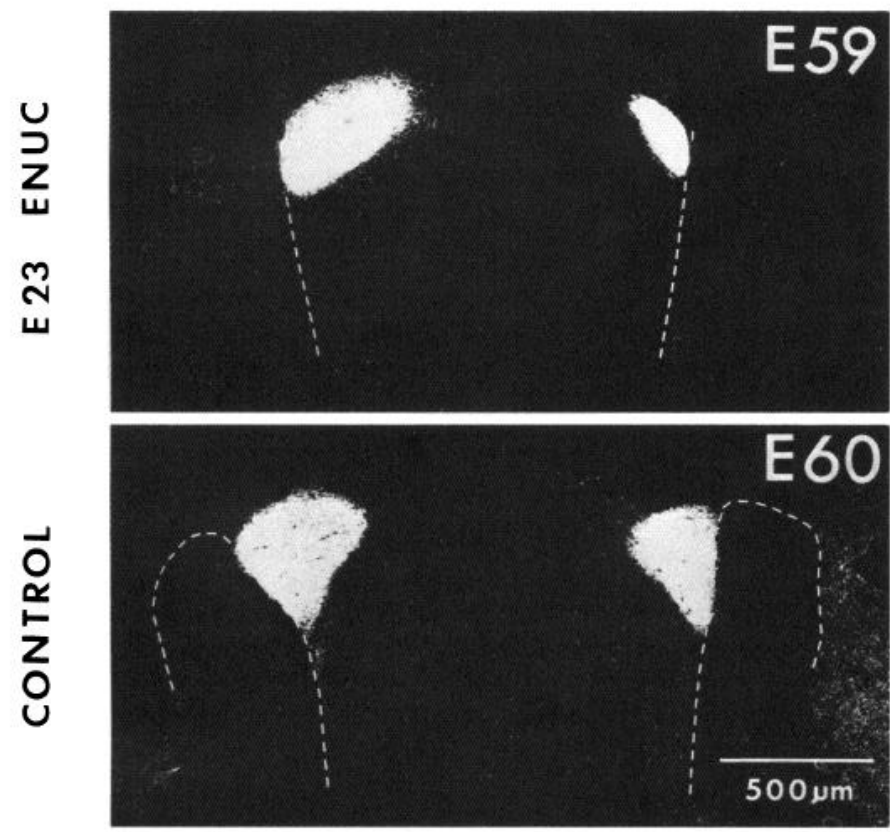

Figure 1. Dark-field autoradiographs of the labeling pattern in the optic tracts contralateral and ipsilateral to an intraocular injection of ${ }^{3} \mathrm{H}$-leucine. Top, Animal examined at E59 following unilateral enucleation at E23. Bottom, Control animal examined at E60. Both horizontal sections are taken approximately $400 \mu \mathrm{m}$ dorsal to the optic chiasm. The dotted white lines delineate the outline of the diencephalon. Although the contralateral optic tract appears to be of normal size in the enucleated case, the ipsilateral tract occupies a smaller cross-sectional area. In the E60 control, portions of the temporal lobe can be seen at the left and right sides of the photo. The temporal lobes in the enucleated case were dissected away in order to label optic tract axons with HRP. (The reconstructed terminal arbors of some of the axons from this enucleated fetus are shown in Fig. 9.)

$48-72 \mathrm{hr}$ at $4^{\circ} \mathrm{C}$. (Time elapsed from the delivery of the fetus to immersion fixation of the nerve was approximately $10 \mathrm{~min}$.) It is worth noting that the same dissection procedure is used for physiological studies (Shatz and Kirkwood, 1984) in which the optic nerve remains viable

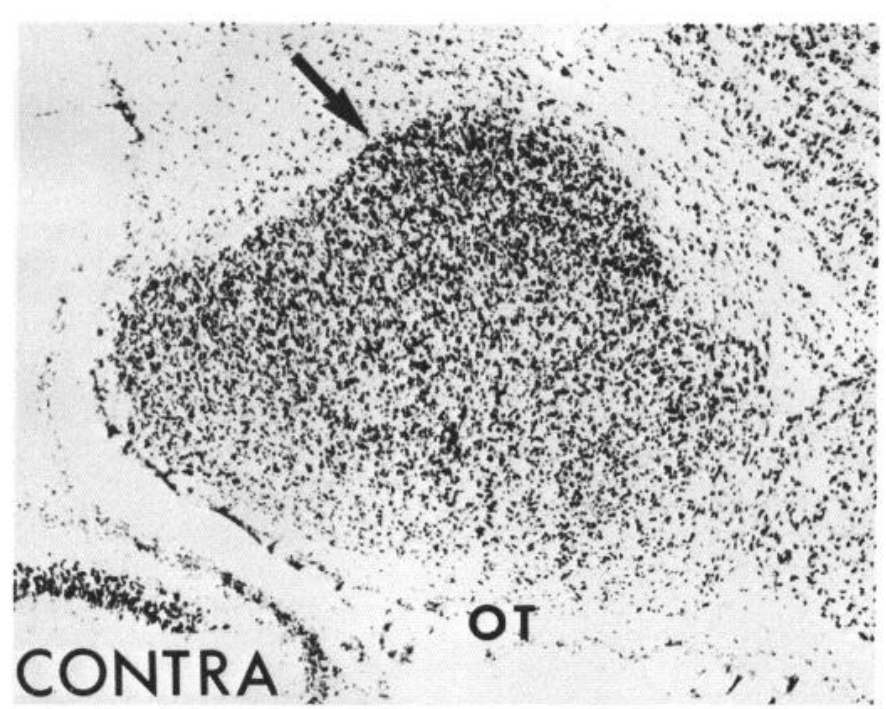

for many hours. The nerves were then osmicated $\left(1 \% \mathrm{OsO}_{4}\right.$ in $0.1 \mathrm{M}$ phosphate buffer), block-stained with $0.5 \%$ uranyl acetate, and embedded in Spurr embedding medium (Polysciences, Inc.). Thin sections were placed on a 300 mesh copper grid and stained with $0.5 \%$ uranyl acetate followed by $0.2 \%$ lead citrate. Fixation by immersion or perfusion produced adequate ultrastructural detail required for axon counts (see Fig. 10). Estimates of the number of axons in the optic nerve were determined using the method of systematic grid analysis described in $\mathrm{Ng}$ and Stone (1982) and Williams et al. (1983b). This method involves the systematic sampling of all areas of the optic nerve at set intervals determined by the 300 mesh grid spacing. From approximately 100 micrographs for each nerve, the average number of axons per unit area was computed. This number was then multiplied by the total area of the optic nerve to obtain an estimate of the total number of axons in the nerve.

\section{Retinal whole-mount}

The retina of one of the monocularly enucleated fetuses was prepared as a whole-mount at E59 and stained with cresyl violet to examine the distribution of ganglion cells across the retina. After removal of the cornea, the eye was immersion-fixed overnight in $4 \%$ paraformaldehyde and then prepared using standard retinal whole-mount techniques (Stone, 1978). All ganglion cells were counted while viewing the retina using a $63 \times$ oil immersion objective (N.A. 1.4). To examine the density distribution of retinal ganglion cells along the nasotemporal axis, all ganglion cells within a $100 \mu \mathrm{m}^{2}$ area at $400 \mu \mathrm{m}$ intervals along this axis were counted.

\section{Results}

The results presented here are based on eight normally pigmented animals, each of which had one eye removed on E23. At the time of analysis (E59), each animal appeared to be well formed with a range of crown-rump lengths (110-130 mm) normal for its age (Shatz, 1983). On the enucleated side, the cranium was smooth, with almost no hint of an orbit. However, superficial structures such as eyelids were present. The gross appearance of the brain itself also was also normal, and both the telencephalon and diencephalon were symmetrical. As expected from the early monocular enucleations, only one optic nerve was present.

\section{Optic tracts after early monocular enucleations at E23}

In the experimental fetuses, retinal axons grow into the optic chiasm without encountering axons from the other eye, a situation not found during normal development. Nevertheless, fe-

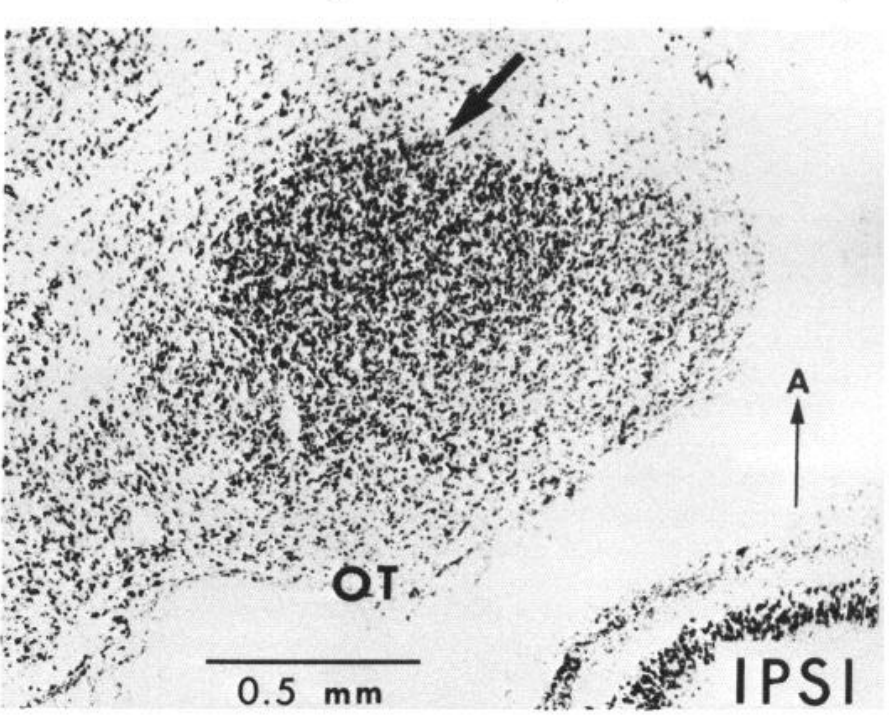

Figure 2. Nissl-stained horizontal sections through the contralateral and ipsilateral LGN of an E59 fetus that had one eye removed at E23. The nucleus contralateral to the remaining eye (CONTRA) appears normal in size and shape and its innermost boundary (large arrow) is well defined. The ipsilateral nucleus (IPSI), on the other hand, appears slightly smaller and its innermost border (large arrow) is less well defined. OT, Optic tract; $A$, anterior. 

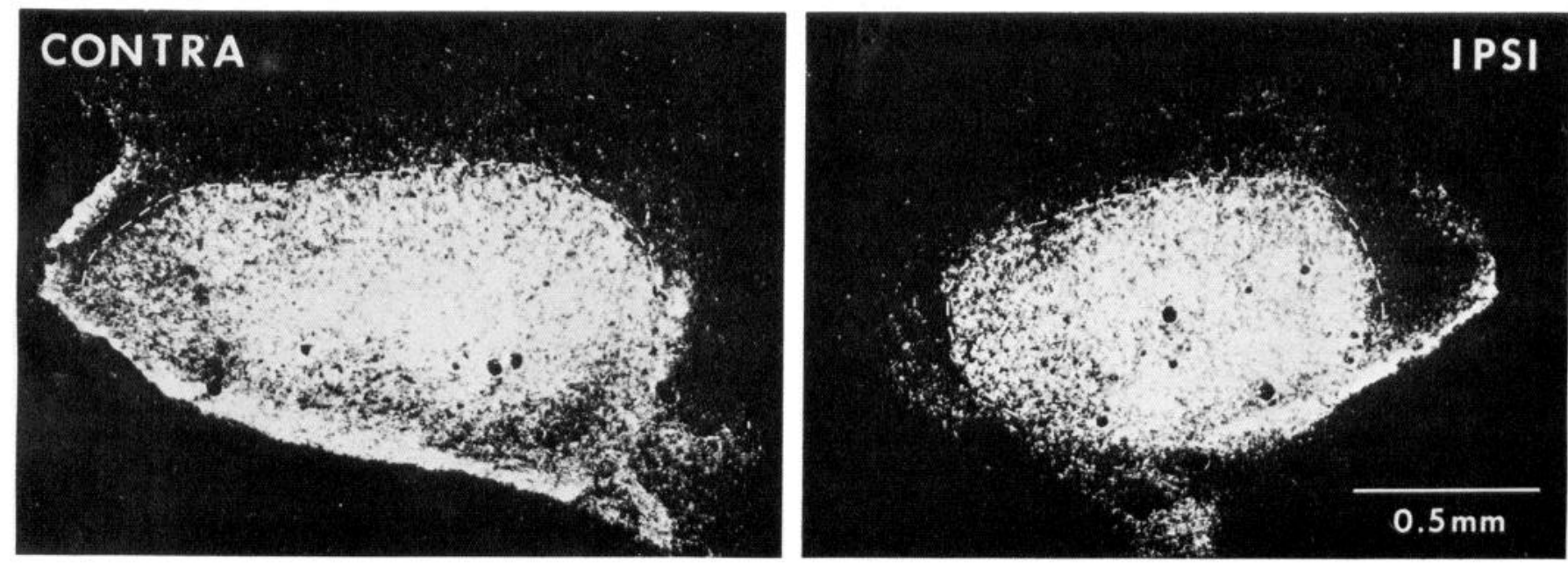

Figure 3. Dark-field autoradiographs showing the labeling pattern in the LGN of an E59 fetus that had one eye removed at E23 and received an intraocular injection of ${ }^{3} \mathrm{H}$-leucine in the remaining eye at E58. Both LGN contralateral (CONTRA) and ipsilateral (IPSI) to the surviving eye appear to be covered completely by radioactive label. On both sides, however, there are regions of slightly sparser and slightly denser labeling. The white dashes mark the inner border of the nucleus in these horizontal sections. Sections oriented as in Figure 2.

tuses with one eye removed had both a contralateral and an ipsilateral optic tract. The optic chiasm and tracts were also located in the appropriate positions at the ventral base and along the lateral surface of the diencephalon. An example of the pattern of labeling within the optic tracts following an intraocular injection of ${ }^{3} \mathrm{H}$-leucine in an E59 animal that had one eye removed at E23 is shown in the autoradiographs of Figure 1. Results from a control animal at the same age are shown in the lower half of the figure for comparison. In both cases, a horizontal section approximately $400 \mu \mathrm{m}$ dorsal to the optic chiasm is shown; the dotted lines depict the outline of the diencephalon.

In the experimental case, the contralateral optic tract appears rather similar in cross-sectional area to the normal control. On the other hand, the ipsilateral tract occupies a substantially smaller area than normal. It is possible that early eye removal results in a smaller number of axons in the optic tract ipsilateral to the surviving eye. Alternatively, in the absence of axons from the other (removed) eye, the ipsilateral axons may coalesce to occupy a smaller cross-sectional area within the optic tract.

\section{Retinal projection to the $L G N$}

Even though the LGN is supplied by afferents from only one eye in the monocularly enucleated fetuses, the LGN both contralateral and ipsilateral to the remaining eye appeared fairly well formed at E59. Figure 2 shows horizontal sections taken approximately through the middle of the contralateral and ipsilateral lateral geniculate nuclei in an enucleated animal. On both sides, the optic tract (OT) runs along the posterior and lateral surface of the LGN. The LGN contralateral to the surviving eye is of approximately normal size and shape for this age (cf. Shatz, 1983, Fig. 9). The innermost boundary of the LGN (see arrow) is sharply defined, and the adjacent perigeniculate nucleus can be identified as a halo of cells just outside this boundary. In contrast, the ipsilateral nucleus is slightly smaller than normal and than its contralateral counterpart. In addition, the innermost boundary of the ipsilateral LGN appears to be less well defined (see arrow). It is worthwhile pointing out that the ipsilateral nucleus appeared to be variably but consistently smaller in its dorsal-to-ventral extent, as well as its mediolateral extent when compared to the contralateral nucleus.

Intraocular injections of ${ }^{3} \mathrm{H}$-leucine show that the pattern of the retinogeniculate projection from the remaining eye is very different from normal. In normal fetuses at E59, afferent input from the two eyes to the LGN has already sorted out from the earlier immature pattern. Thus, an intraocular injection in a normal fetus at this age results in the labeling of only certain regions of the nucleus, i.e., those layers occupied by afferent terminals from the injected eye. Intervening layers occupied by afferents from the other eye are devoid of label (see Shatz, 1983; Fig. 8A). In enucleated animals, both the contralateral and the ipsilateral LGNs are completely filled with label, indicating that all parts of the LGN are occupied by retinal afferents from the remaining eye. An example of this labeling pattern is shown in the dark-field autoradiographs of Figure 3. Although the contralateral nucleus (Fig. 3, left) is completely filled with label, the labeling density does not appear to be totally even; zones of heavier and lighter label are often encountered within the LGN. For instance, it was our impression that the middle third of the nucleus (the zone corresponding to layer A1 in normal fetuses) was more heavily labeled than elsewhere. The projection to the ipsilateral nucleus also occupies nearly completely the entire nucleus, but the overall area of the ipsilateral projection is smaller than that found on the contralateral side, in accordance with the diminished size of the LGN ipsilaterally. Again there are hints of unevenness in the labeling pattern. The projection to the innermost border of the ipsilateral nucleus also appears to be faint and less distinct than that seen on the contralateral side. These results show that in the cat after early eye removal, as in other mammals after later enucleations (Rakic, 1981; Chalupa and Williams, 1984; So et al., 1984), the afferent projection from the surviving eye fails to become restricted and instead is distributed throughout the entire LGN.

\section{Arborization pattern of individual retinogeniculate afferents}

The complete labeling of the LGN following intraocular injection in enucleated animals could arise if individual retinogeniculate axons have abnormally widespread branching patterns, a situation that might occur if binocular interactions between afferents from the two eyes are required for axons to develop a restricted adult-like pattern of terminal arborization. To investigate this possibility, we filled individual retinogeniculate axons in monocularly enucleated fetuses at E59 with HRP using the in vitro labeling method.

In every animal in which we knew that the retinogeniculate projection covered the entire LGN as revealed by the intraocular injections, it was remarkable that individual retinogeniculate axons were nevertheless restricted in their pattern of terminal 

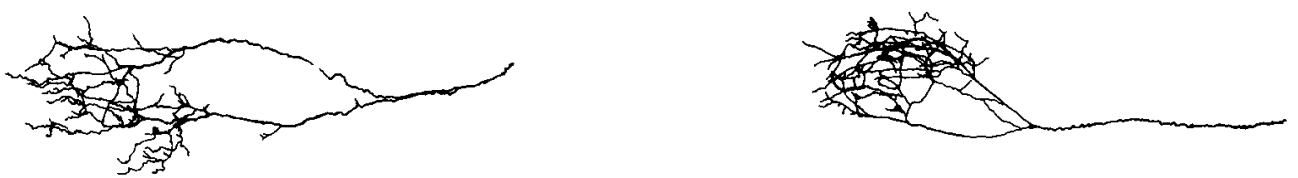

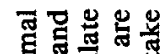

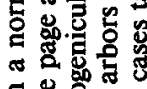

봉응
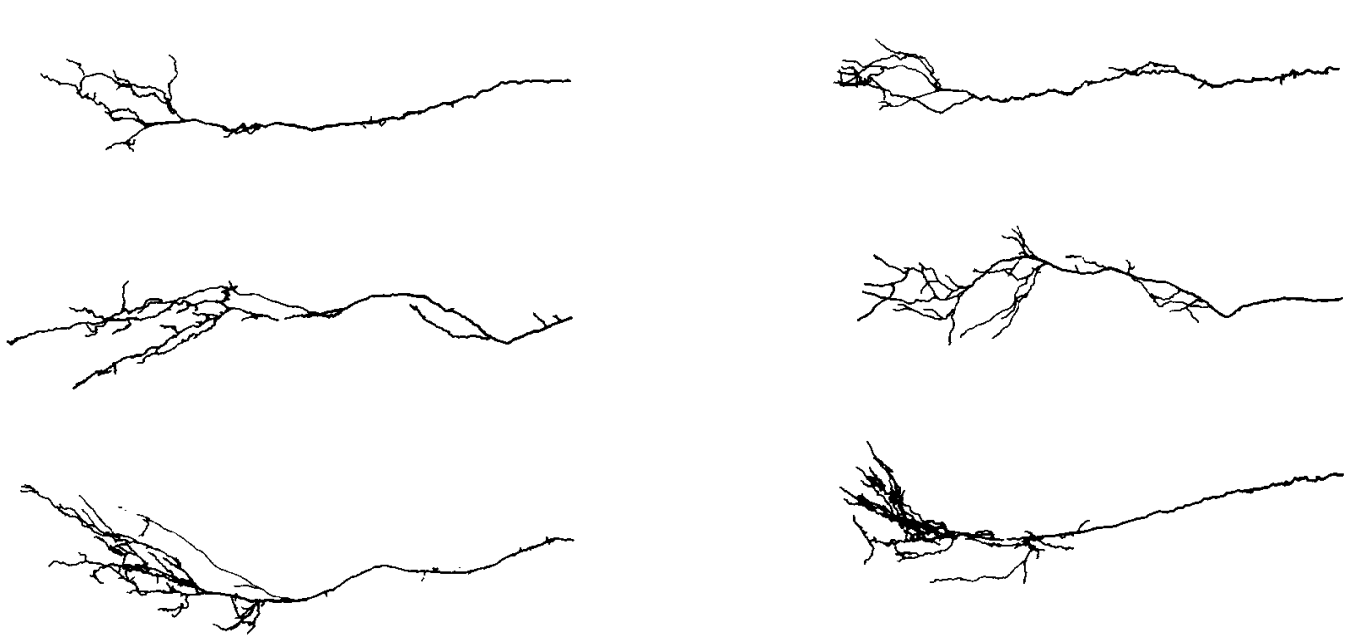

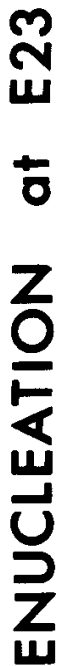

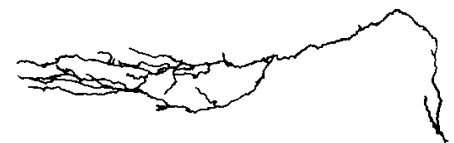

$\overrightarrow{0}$
$\underline{\underline{0}}$
$\mathbf{z}$
$\mathbf{U}$

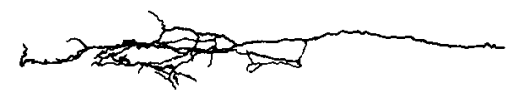

in

U
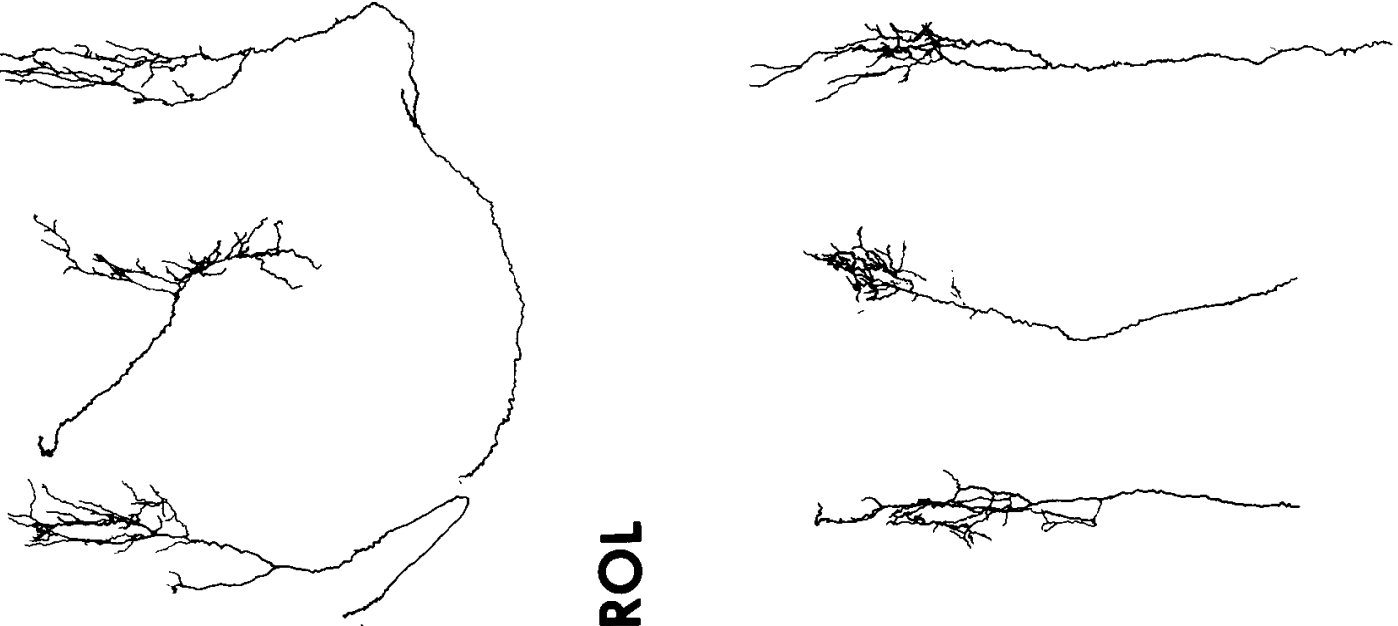

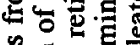

象

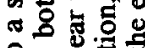

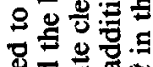

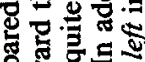

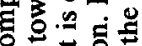

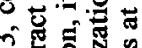

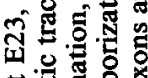

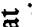

\%

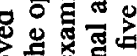

政

政

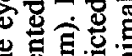

ธ동용

콩웡

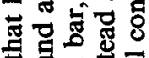

趿象象

昰量胥

눙용

要要

o

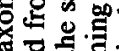

ษ 월월

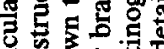

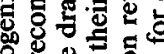

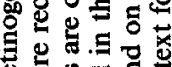

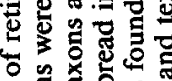

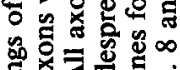

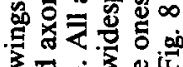

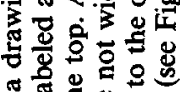

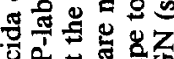

을 후영

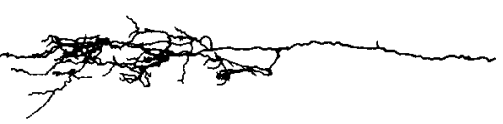

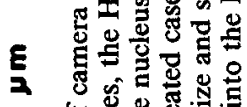

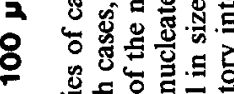

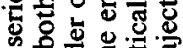

$\infty$

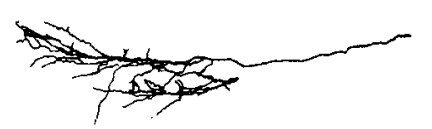

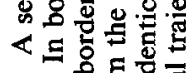

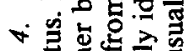

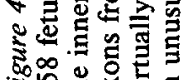

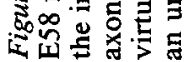




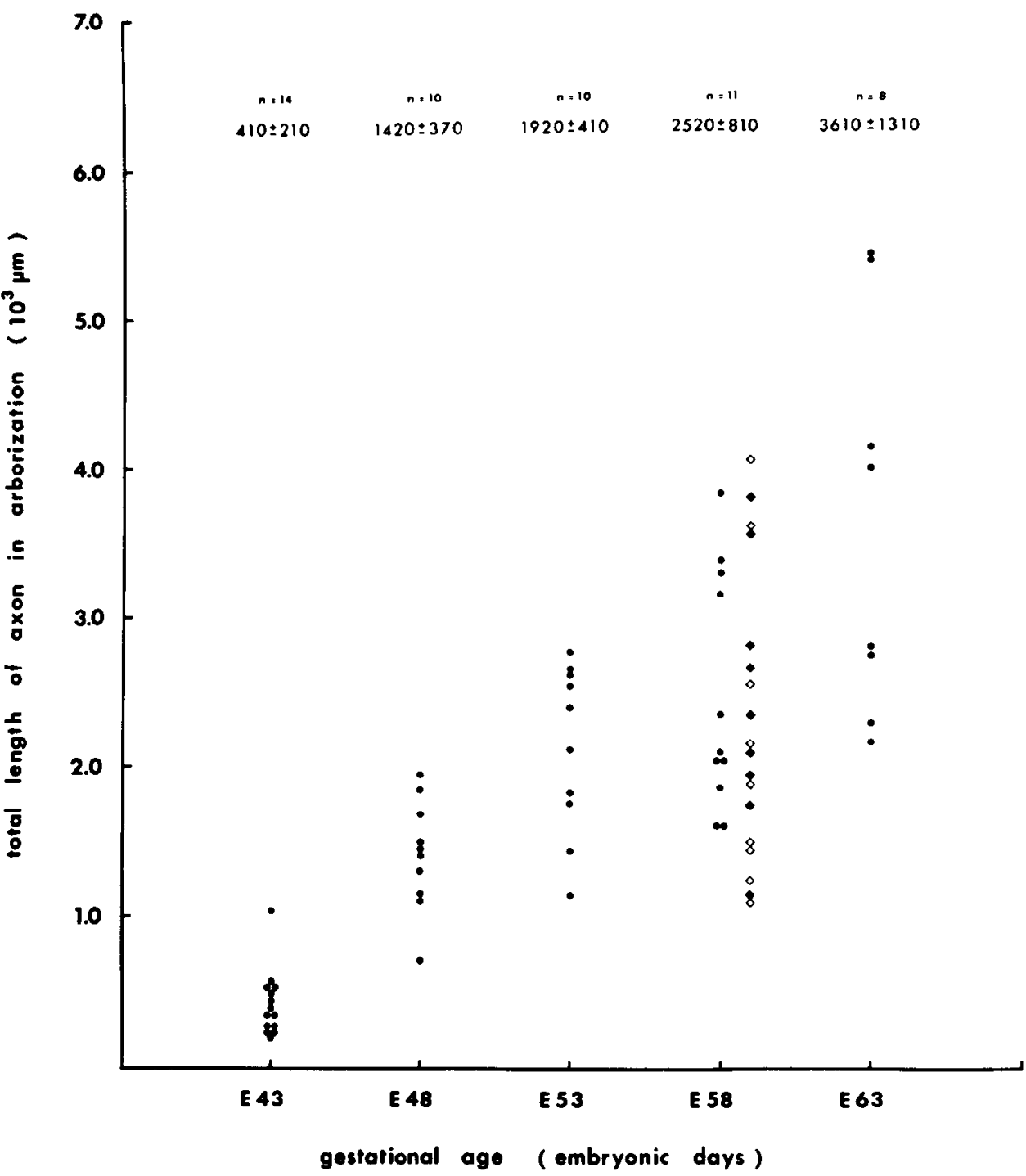

Figure 5. Graph showing the relationship between the total linear length of axon contributing to the terminal arbor and developmental age. The black dots represent measurements of total terminal arbor length in axons taken from a previous study of normal retinogeniculate development and illustrate the roughly linear increase in axon arbor length with developmental age (Sretavan and Shatz, 1986). Measurements of axons from early monocularly enucleated animals in the present study are shown by diamonds. Open diamonds represent axons found in the LGN ipsilateral to the surviving eye; black diamonds represent axons in the contralateral nucleus. Results from the enucleated animals fall well within the normal range, indicating that retinogeniculate axons developing within the LGN in the absence of afferents from the other eye are neither retarded nor accelerated in their growth. arborization in a manner similar to that seen in normal axons at the same age. This finding is shown in Figure 4 , in which a series of terminal arbors of retinogeniculate axons reconstructed from the enucleation cases are compared with a series of axons taken from a normal control fetus at a similar age (E58). [The normal axons are part of another study of the normal development of retinogeniculate afferents (Sretavan and Shatz, 1986).] In this figure, all afferents are drawn at the same scale and are placed at the same orientation, with the optic tract toward the bottom of the page and the inner border of the LGN toward the top. A simple comparison reveals that retinogeniculate afferents from the enucleated animals have terminal arbors that are almost identical in size and shape to those of normal control animals. In both cases, the portion of the axon nearest the optic tract is smooth and unbranched, while heavy branching occurs only within the terminal arbor at the distal portion of each axon. Furthermore, terminal arbors are quite narrow and cylindrical in shape in enucleated and control animals alike. The only obvious difference between the two is that in enucleated animals the trajectory taken by some axons within the LGN en route to the terminal arbor is unusual (see first five axons in the upper right of this figure and also Fig. 8).

We wondered whether these qualitative impressions could be confirmed quantitatively. In an earlier study, we found that the total linear length (amount) of axon contributing to the terminal arbor correlates well with developmental age (Sretavan and Shatz, 1986). This measurement is therefore a good index of the maturity of each retinogeniculate axon. In Figure 5, measurements of the terminal arbors of retinogeniculate axons from our enucleated animals are compared with a set of measurements from normal retinogeniculate axons. Black dots represent the total linear length of axon contributing to the terminal arbors of normal retinogeniculate afferents. With increasing developmental age, there is roughly a linear increase in the net amount of axon contributing to the terminal arbor. For comparison, measurements at E59 of 18 retinogeniculate axons from enucleated animals are plotted onto this graph using black and white diamond symbols. White diamonds represent afferents measured in the ipsilateral nucleus, while black diamonds represent contralateral afferents. The results from the enucleation experiments fall well within the normal range of axon terminal growth for their developmental age, indicating that retinogeniculate axons in enucleated animals are neither retarded in their growth nor excessively large for their developmental age.

\section{Spatial organization of retinogeniculate afferent} terminals within the LGN

In the course of examining the restricted branching patterns of retinogeniculate afferents in the enucleated animals, it became evident that the terminal arbors were not randomly distributed 

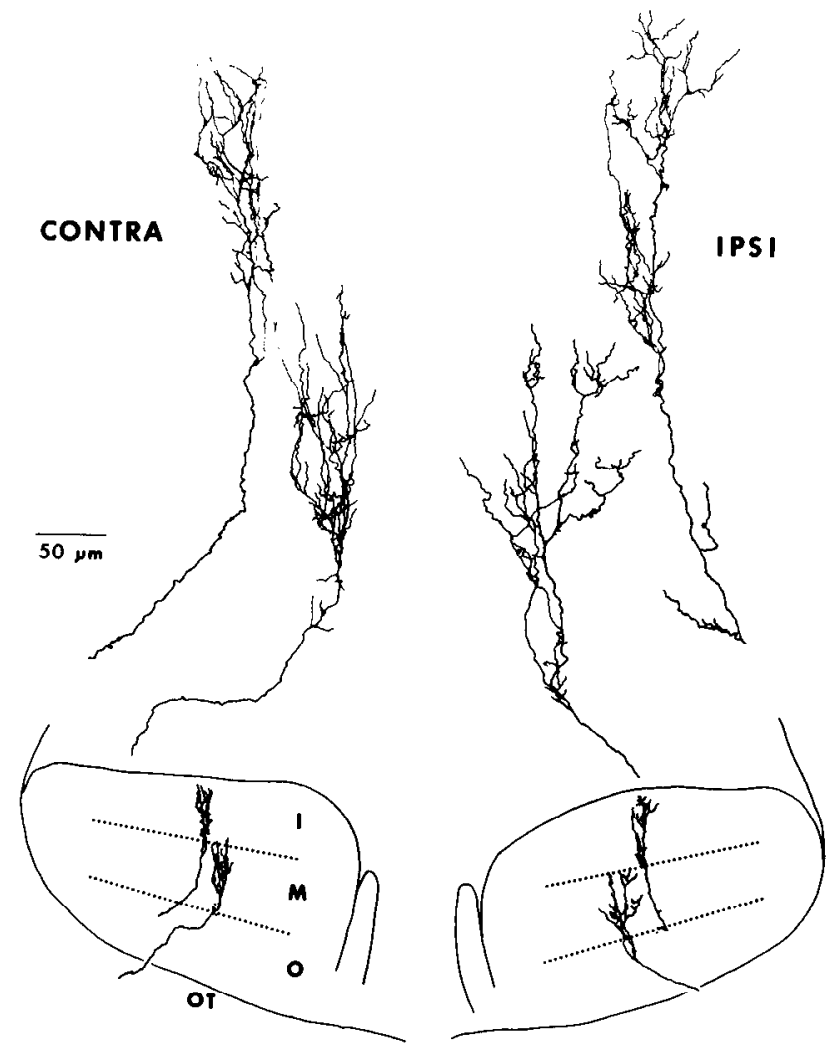

Figure 6. Four retinogeniculate axons reconstructed from an E59 fetus that had one eye removed at E23 to show axons with terminal arbors restricted to either the inner or middle third of the nucleus. The terminal arbors of each pair of axons in the LGN contralateral and ipsilateral to the remaining eye were located in the same $100-\mu \mathrm{m}$-thick section. The locations of the terminal arbors with respect to the nucleus are shown below. Dotted lines demarcate the inner $(I)$, middle $(M)$, and outer $(O)$ third of the nucleus. One axon of each pair arborizes in the inner third of the LGN, while the other arborizes in the middle third. $O T$, Optic tract.

throughout the LGN. For example, in both the contralateral and ipsilateral LGN, reconstructed axons arborized either within the inncr third or within the middle third of the nucleus but never spanned both inner and middle thirds. This arrangement is shown in Figure 6. Here, the LGNs contralateral and ipsilateral to the remaining eye are outlined, and in each LGN, two retinogeniculate axons have been reconstructed. Each pair of axons had the major parts of their terminal arborizations confined to the same $100-\mu \mathrm{m}$-thick section. Dotted lines indicate approximately the inner, middle, and outer (closest to the optic tract) thirds of the nucleus. As can be seen, one axon in each nucleus terminates within the inner third of the nucleus, while the other axon terminates within the middle third of the nucleus. Thus, as expected from the eye-injection experiments, individual axons from the remaining eye do innervate regions of the nucleus that are normally only occupied by afferents from the other eye. However, the unexpected finding is that this innervation is in the form of a very precise and restricted set of terminal arborizations.

This observation that terminal arbors seem to be localized to either the inner or middle third of the nucleus suggests that all afferents from the remaining eye may distribute their terminal arbors into one of three tiers within the LGN. This suggestion is supported in cases where a sufficient number of neighboring axons could be reconstructed to show that the terminal arbors of four or five axons are found grouped next to each other within such a tier. An example of this tier-like arrangement is shown

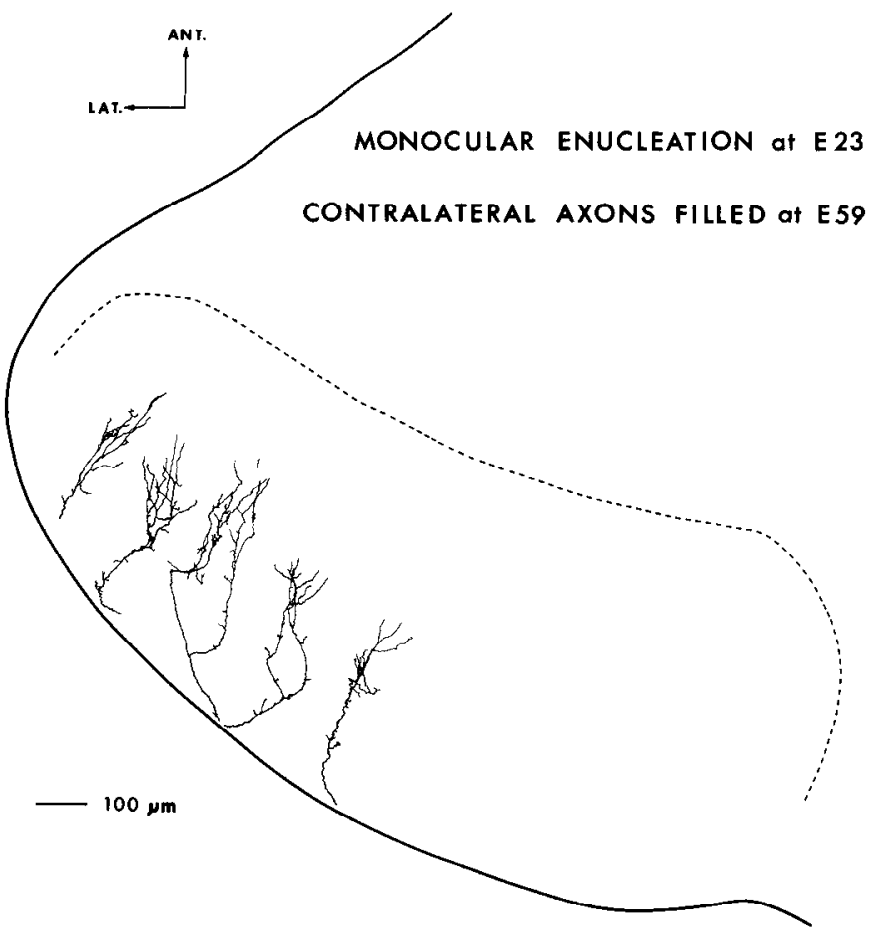

Figure 7. A group of five retinogeniculate axons in the LGN contralateral to the remaining eye. All five axons had the major portion of their terminal arborization located within the same sections, and, when reconstructed, all have terminal arbors that collectively form a tier located approximately in the middle third of the nucleus. $A N T$, Anterior; $L A T$, lateral.

in Figure 7. Here, five axons from the remaining eye that project to the contralateral LGN are shown. The main portions of the terminal arborizations of all five afferents were located in and reconstructed from the same adjacent sections. Each of these axons runs into the LGN from the optic tract below to arborize within the nucleus. However, the afferents do not traverse all the way across to the inner border of the LGN, but rather elaborate a discrete terminal arborization within the middle portions of the LGN. Together, the terminal arbors of all five axons are arranged in a ticr parallel to the optic tract in a fashion very reminiscent of the arrangement of terminal arbors from the ipsilateral eye within layer A1 of normal fetuses (cf. Sretavan and Shatz, 1986, Fig. 14B).

In another part of the same LGN, a separate set of four axons were reconstructed together, and their terminal arbors were found to form a tier in the inner third of the nucleus (Fig. 8). In addition to this group of four axons, the terminal arborizations of a fifth axon within the same section were found located in the middle third of the LGN not overlapping the zone of termination of the other four axons. The afferents shown in this figure illustrate another unusual feature occasionally seen in some enucleated animals. All four axons belonging to the innermost tier take an abnormal route to their sites of termination. Instead of entering the LGN from the optic tract below and running radially across the nucleus in the usual manner (Sretavan and Shatz, 1986), these axons leave the optic tract just adjacent to the anterolateral corner of the nucleus and follow an abnormal tangential route across the LGN. Despite this unusual route, the axons still form terminal arbors of normal size and orientation, with the long axis of their terminal arbors perpendicular to the plane of the tiers (or layers).

Evidence for a tier-like arrangement of arbors within the ipsilateral nucleus is less clear but nevertheless suggestive. Figure 9 shows a group of ipsilaterally projecting axons from the re- 


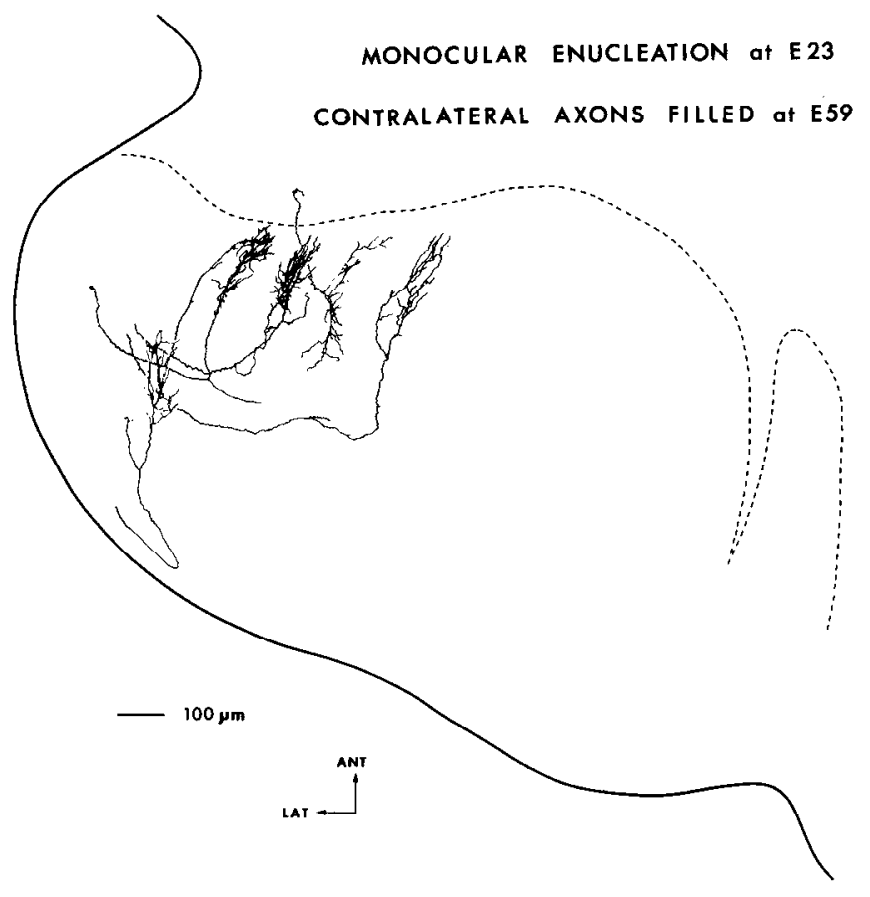

Figure 8. A group of five axons in the LGN contralateral to the remaining eye. These axons were from the same LGN as in Fig. 7 but were located in a more ventral portion of the nuclcus. The terminal arbors of four axons form a tier in the inner third of the nucleus. A fifth axon has its terminal arbor located in the middle third of the nucleus, not overlapping the terminals of the other four axons. These four axons also take an unusual route into the LGN: Instead of entering the LGN from the optic tract below, they originate from the optic tract adjacent to the anterolateral corner of the nucleus.

maining eye. Two afferents arborize in the middle third of the nucleus, while three others arborize within the inner third of the nucleus. The single axon located at the lateral end of the nucleus was the only one encountered in this study that did not have a restricted arborization. Instead, it had many short side branches given off throughout its main axon trunk.

To sum up so far, it is clear from the results presented above that interactions between afferents from two different eyes are not strictly necessary for retinogeniculate axons to acquire a normally restricted pattern of terminal branching. There are several ways in which this result may be interpreted. First, perhaps retinogeniculate afferents intrinsically form restricted terminal arbors of a predetermined size as part of a hard-wired developmental program and thereforc can never cxpand over a large amount of LGN territory made available in enucleated animals. Alternatively, a restricted branching pattern might be produced as a result of interactions occurring among the retinal ganglion cells of the remaining eye.

\section{Number of axons in the remaining optic nerve}

One of the ways in which retinogeniculate afferents from the same eye might interact with each other to produce a restricted branching pattern could be simply through a crowding effect due to the presence of abnormally large numbers of afferents in the LGN competing for limited terminal space. It is known that during the normal prenatal development of the cat's visual system, more than $70 \%$ of the axons originally present in the optic nerve are eliminated ( $\mathrm{Ng}$ and Stone, 1982; Williams et al., 1983a). If this loss results from binocular competition within the targets, as has been suggested (Rakic, 1981; Rakic and Riley, 1983a, b; Williams et al., 1983b), the early removal of one eye, as in our experiments, might save a large number of axons in the remaining optic nerve that would otherwise have been eliminated.

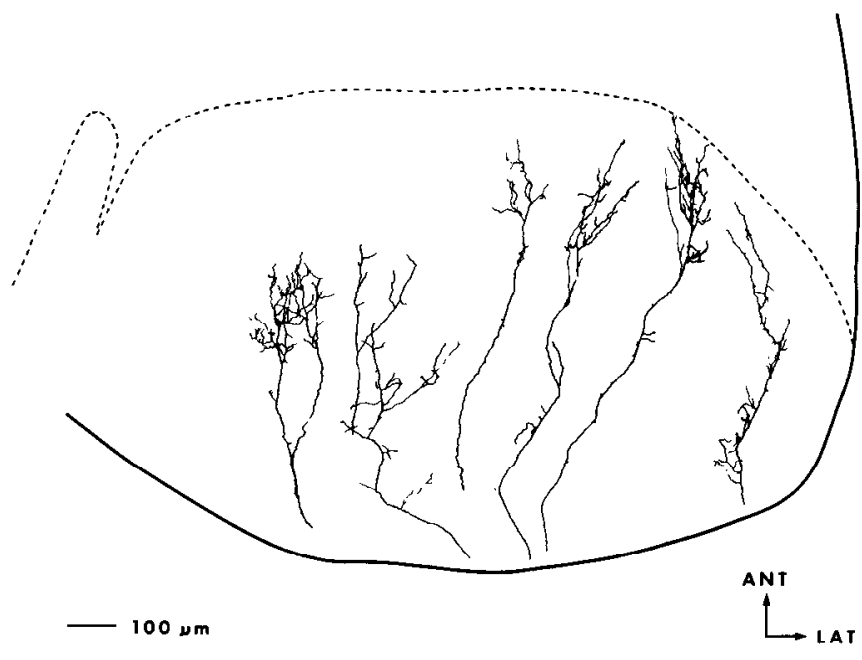

Figure 9. A group of six axons from the LGN at E59 of an E23 monocularly enucleated fetus ipsilateral to the remaining eye. The major part of each axon's terminal arbor was located in the same sections. The terminal arbors of the two medially located axons are found in the middle third of the nucleus, while three other axons all arborize in the inner third of the nucleus. The most laterally located axon was the only one encountered in this study that did not have a well-defined terminal arbor. Instead, processes are given off throughout the course of its main axon trunk.

This increase in optic axon number could then lead to an increased competition for terminal space within the LGN between axons of the remaining eye, one consequence of which could be restriction of terminal arborizations. To investigate this possibility, we performed a quantitative electron microscopic analysis to determine whether there was an abnormally large number of axons in the remaining optic nerve at E59 following enucleation at E23. The analysis was conducted on two optic nerves from fetuses in which retinogeniculate afferents had also been reconstructed and were known to have a restricted pattern of arborization. Two other optic nerves from normal control fetuses of the same age were also analyzed. The appearance of axons within the optic nerve from an enucleated fetus and a normal control at E59 is shown in the electron micrographs of Figure 10.

The results of this analysis from enucleated and control fetuses at E59 are listed in Table 1. In the first enucleated fetus, there was an cstimated total of 212,000 axons in the remaining optic nerve. This number is very similar to the number of 220,000 obtained in the optic nerve of a normal control animal from the same litter. A second experimental case had an estimated 242,000 optic axons in the remaining nerve, while a second control optic nerve had 269,000 axons. Thus, both the control and enucleated animals had counts close to those of $\mathrm{Ng}$ and Stone (1982)-E57: 275,000; E60: 219,000-and Williams et

Table 1. Estimates of the number of optic nerve axons in animals enucleated at E23 and in control animals

\begin{tabular}{llllll} 
Case & $\begin{array}{l}\text { Age at } \\
\text { enucleation }\end{array}$ & $\begin{array}{l}\text { Age } \\
\text { examined }\end{array}$ & $\begin{array}{l}\text { No. } \\
\text { micro- } \\
\text { graphs }\end{array}$ & $\begin{array}{l}\text { No. axons } \\
\text { counted } \\
(n)\end{array}$ & $\begin{array}{l}\text { Estimated } \\
\text { no. of } \\
\text { axons }\end{array}$ \\
\hline $1^{a}$ & E23 & E59 & 115 & 4714 & 212,000 \\
$2^{a}$ & Control & E59 & 109 & 5821 & 220,000 \\
3 & E23 & E59 & 81 & 3524 & 242,000 \\
4 & Control & E59 & 101 & 4221 & 269,000 \\
\hline
\end{tabular}

Siblings from same litter. 


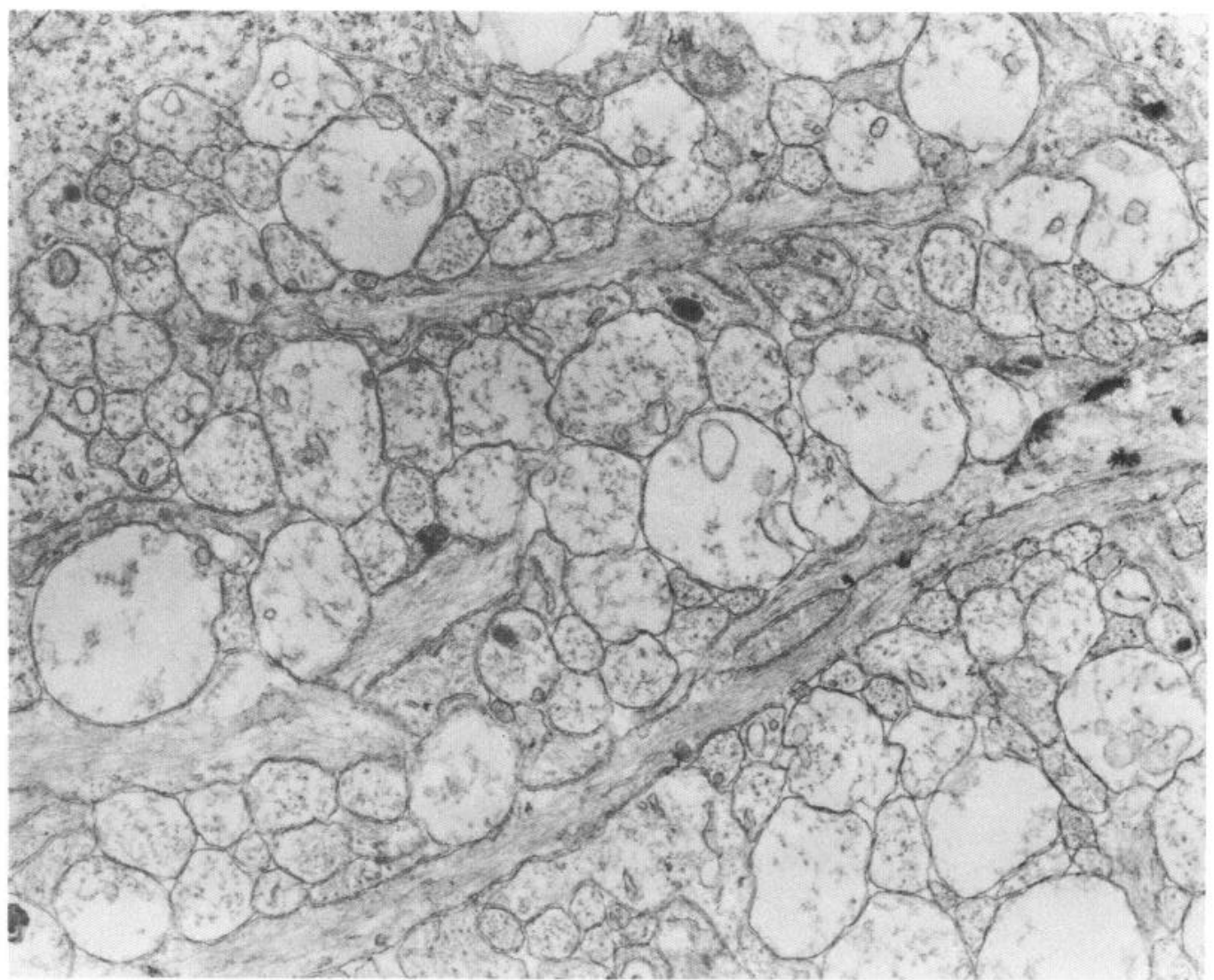

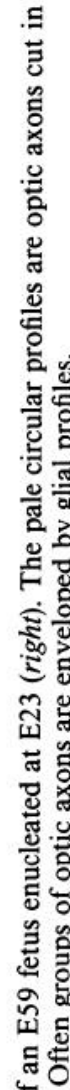

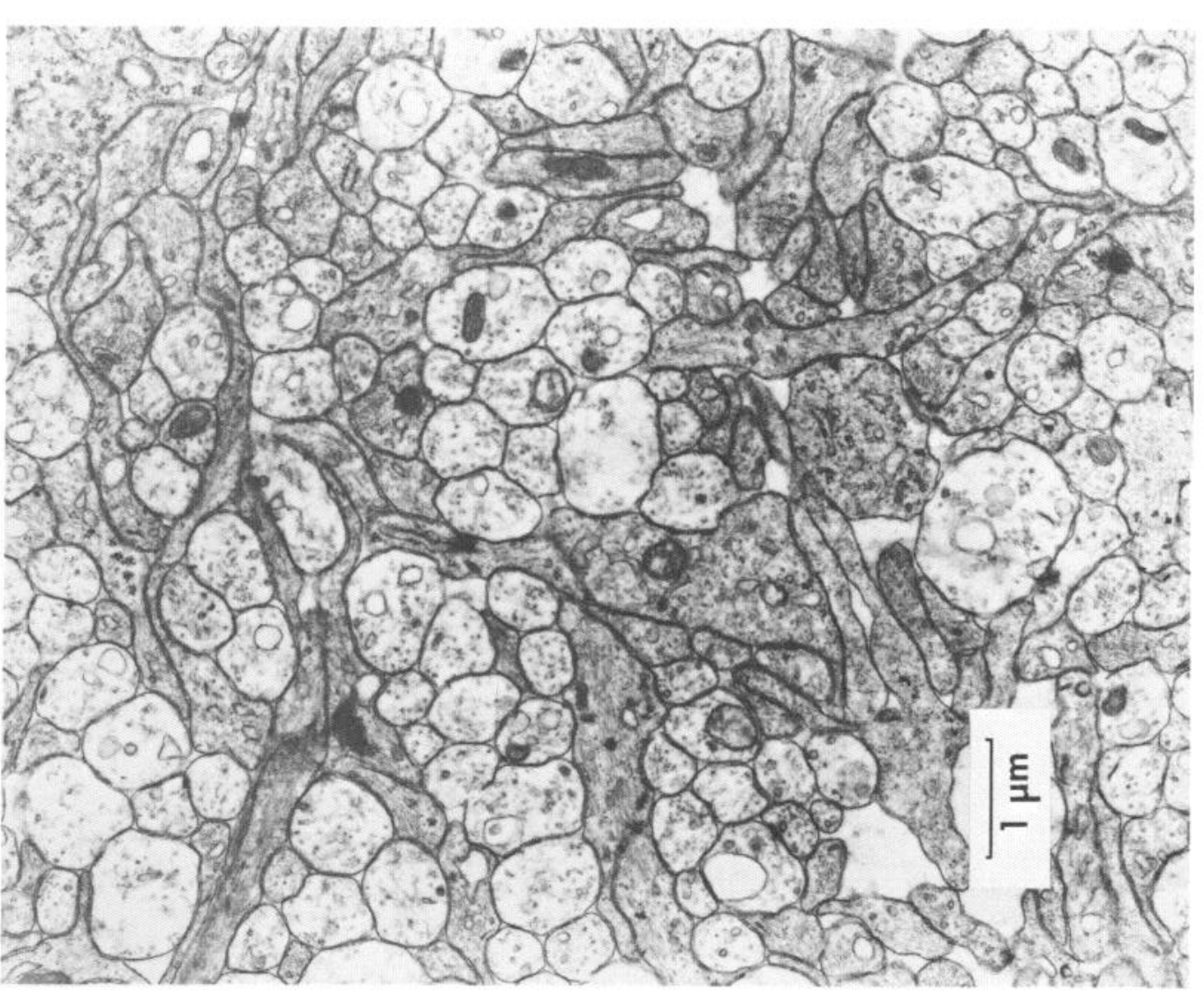

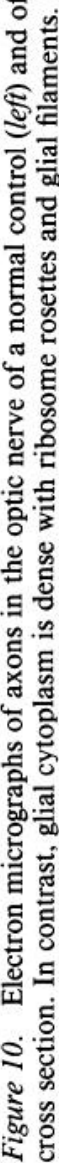


E59 RETINA (other eye enucleated at E 23)
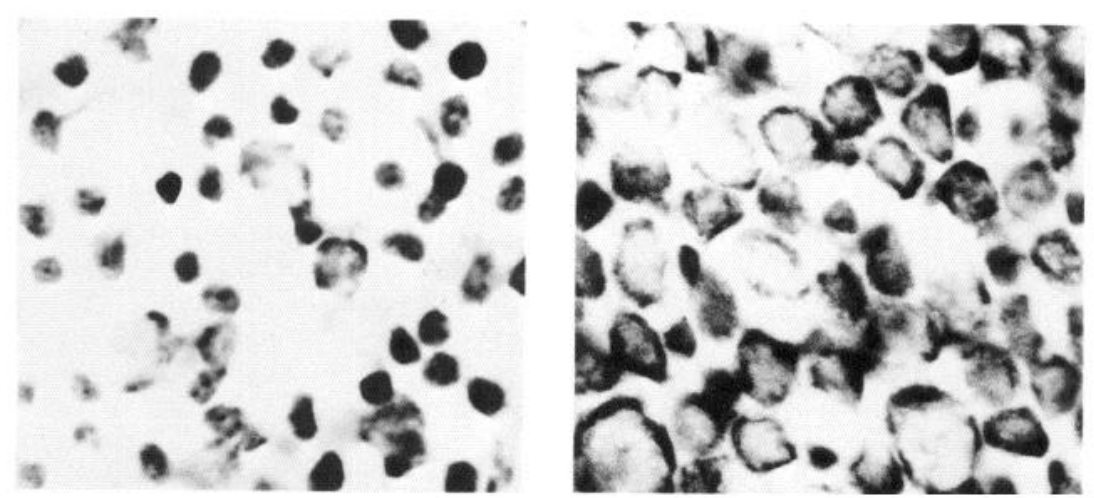

PERIPHERY

$15 \mathrm{Nm}$

A
AREA CENTRALIS

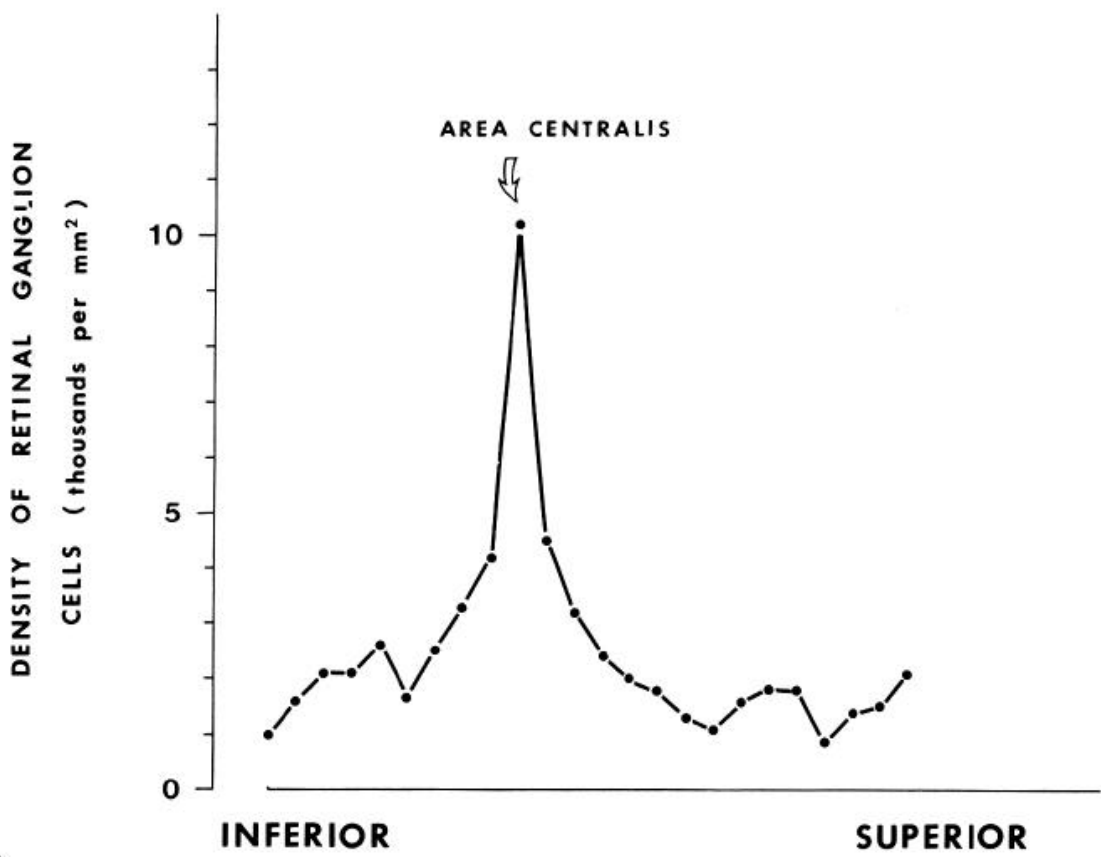

D

al. (1986)-E56: 230,000; E61: 267,000-for normal fetuses. These results demonstrate that early enucleation does not appear to increase greatly the number of axons in the surviving optic nerve. Consequentiy, the restriction in branching of retinogeniculate arbors in monocularly enucleated fetuses cannot be explained simply by the presence of an abnormally large number of axons in the optic nerve, all of which, in turn, might enter the LGN and crowd each other out of territory made available by the absence of the other eye. On the other hand, there are many other factors that might also limit the amount of terminal space available to each retinogeniculate afferent and some of these will be considered in the Discussion.

\section{Discussion}

In this study we have altered the normal retinogeniculate pathway by removing an eye during early fetal life. As a result, only afferents from one eye grow into and innervate both lateral geniculate nuclei, thereby forming an experimental monocular retinogeniculate projection. By doing this, we intended to distinguish between aspects of development in this system that depend on binocular interactions in the target and those that are intrinsic to retinal ganglion cells, or that can be expressed through interactions among retinal ganglion cell axons of one eye alone.

The results of this study indicate that many events occurring during the prenatal development of the retinogeniculate system can still occur in the absence of normal binocular interactions. These include the formation of both an ipsilateral and a contralateral retinogeniculate projection, and the normal massive loss of axons within the optic nerve. Within the LGN, even in the absence of binocular interactions, individual retinogeniculate afferents from the remaining eye can still form restricted terminal arbors normal in size and shape. In addition, although alternate layers belonging to the two eyes are not present, afferent terminals in enucleated animals are segregated into tiers in such a way that regions of the nucleus normally occupied by afferent terminals from the removed eye are now replaced by a layerlike tier of afferent terminals from the remaining eye. 


\section{Formation of an ipsilateral projection}

At the level of a single retinal ganglion cell axon, the optic chiasm represents a pathway choice early in development. Individual growth cones as they arrive at the chiasm are faced with the decision to cross over to the contralateral tract or to enter the ipsilateral tract. To what extent do axons depend on the presence of afferents from the other eye at the chiasm in order to turn into the ipsilateral optic tract? The results here show clearly that in the absence of axons from the other eye at the optic chiasm, a substantial number of retinal axons are still able to enter the ipsilateral tract, indicating that binocular interactions are not necessary to form an ipsilateral projection. Similar results have been obtained in chicks (Ferreira-Berrutti, 1951) and mice (Godement, 1984) and the present finding suggests that the conclusion holds true as well for mammals with extensive binocular connections. This is not to say, however, that during normal development, interactions between afferents from the two eyes do not occur at the chiasm. For instance, the presence of axons from both eyes may be very important in determining the normal and topographically correct pattern of decussation at the chiasm.

\section{Prenatal loss of axons in the cat's optic nerve}

During normal development of the cat's optic nerve, the number of optic axons reaches a maximum of 500,000-600,000 at E40$45(\mathrm{Ng}$ and Stone, 1982; Williams et al., 1983a). Subsequently, about 450,000 axons are eliminated to give rise to the adult number of 150,000 axons. About $80 \%$ of the axons to be eliminated are lost during the 3-4 week period following E45, so that by birth, only about 200,000 axons are present. The remaining $20 \%$ disappear postnatally at a slower rate until the adult number is reached by 1 or 2 months after birth (for further details, see $\mathrm{Ng}$ and Stone, 1982; Shatz and Sretavan, 1986). At present, the reason for the elimination of roughly 450,000 axons is unknown, but it has been suggested that competition between afferents from the two eyes within target nuclei (LGN and superior colliculus) might be responsible (Rakic and Riley, 1983b; Williams et al., 1983b). However, as shown here, the prenatal loss of optic axons still occurs in the remaining retinal projection of fetuses monocularly enucleated prior to optic nerve outgrowth. This observation suggests that the loss of optic axons during normal prenatal development may be regulated by mechanisms other than binocular competition.

Our finding that a normal number of axons is eliminated from the optic nerve in early enucleated animals is actually quite consistent with results from earlier experiments in rat (Crespo et al., 1984; Lam et al., 1982), cat (Williams et al., 1983b), and monkcy (Rakic and Rilcy, 1983b). In thcse cxpcriments, onc eye was removed after the target nuclei had been innervated, and then the number of axons in the remaining nerve was examined at later developmental times or in adult animals. For example, in cats (Williams et al., 1983b), when the animals were examined as adults after late fetal eye removal, only about $10 \%$ of the axons that normally would have died during development were actually saved. In our study and those in rat (Crespo et al., 1984; Lam et al., 1982), no difference in the number of optic nerve axons between enucleated and control animals could be found; in other words, suggesting that no axons were saved. One explanation for this discrepancy is that, at least in our study, the variability inherent in the optic nerve counts (see Table 1) is sufficiently great that a difference of $10 \%$ could easily be obscured. Since much of the variability is likely to arise from differences in the exact developmental age from litter to litter, one way to minimize it is to examine both control and enucleated fetuses from the same litter. Although we were able to do this only once, we did find good agreement between the counts in both animals, suggesting that early enucleation in the cat may not alter at all the normal prenatal loss of axons in the remaining nerve.

Another more important consideration is that in our experiments and those performed in rat, the effects of enucleation were examined at some later time during development rather than in adulthood. It should be noted that we examined the optic nerve at E59, a time when normally about $80 \%$ of the axon loss has already occurred; the remainder is then lost between E59 and 1-2 months postnatally. This observation raises the possibility that binocular interactions may come into play primarily during this later phase of axon loss, thereby accounting for the discrepancy between the results of earlier studies in which the number of optic axons was counted in the adult animal and our results. Thus, it now appears that, at least in cat, the major loss of axons from the optic nerve during development can occur largely independently of the effects of binocular interactions, since it cannot be prevented by either early or late eye removal. However, binocular interactions may be involved in regulating a small proportion of this loss since, as mentioned above, eye removal does save about $10 \%$ of the axons. Whether binocular interactions become important only during the later, more gradual phase of axon loss requires further study.

If axon loss is largely independent of binocular interactions, then it might occur as a consequence of mechanisms intrinsic to the pathway from a single retina. If so, the question arises as to what developmental change or changes are reflected in this massive loss of optic nerve axons. One possibility is that the axon loss is related directly to the death of retinal ganglion cells associated with the establishment of topographic order. For example, in the development of the rat's retinocollicular projection, it is known that ganglion cells projecting to topographically inappropriate regions of the superior colliculus are eliminated by cell death (Insausti et al., 1984; O'Leary et al., 1984; for review, see Shatz and Sretavan, 1986).

Another example of topographically related cell death may be the creation of the central-to-peripheral gradient in ganglion cell density during development. The adult gradient in centralversus-peripheral retinal ganglion cell density (Stone, 1965, 1978) is derived from an earlier immature pattern of uniform cell density across the retina (Stone et al., 1982). In support of the idea that cell death plays a role in this aspect of retinal topography, it is known that an 18:1 central-to-peripheral gradient in ganglion cell density is apparent by E57, toward the end of the rapid phase of axon loss in the nerve (Stone et al., 1982). In addition, there is preferential loss of retinal ganglion cells from peripheral retina during development (Kliot and Shatz, 1982; Sengelaub and Finlay, 1982; Stone et al., 1982; for review, see Shatz and Sretavan, 1986).

In this context, it is worthwhile mentioning that the centralto-peripheral gradient of ganglion cell density is still established in the absence of binocular interactions. For example, Chalupa et al. (1984) have shown that monocular enucleation at E42 does not prevent the development of the gradient. We have obtained similar results even when the enucleation is pcrformed at E23. In one such animal in which the optic nerve was prepared for EM (case no. 3, Table 1), the retina was also prepared as a whole-mount. Analysis showed that there was a normal peak density of 10,000 cells $/ \mathrm{mm}^{2}$ at the area centralis and that the gradient in central versus peripheral retina was also normal: The density of retinal ganglion cells in central retina was about $20 \times$ that in peripheral retina (cf. Stone et al., 1982). These results are shown in Figure 11 and further support the suggestion made above that axon loss may be due to interactions among the ganglion cells of one retina.

The exact nature of these intraretinal interactions is, of course, unknown. But one such set of interactions between ganglion cells has already been described (Linden and Perry, 1982; Perry and Linden, 1982). In those studies, it was found that dendrites 
of retinal ganglion cells in newborn rats are able to increase their territory when nearby ganglion cells are destroyed, suggesting that dendrites interact or compete with each other, presumably for presynaptic inputs. This kind of competition could result in ganglion cell death, although at present it is completely unknown whether dendritic competition contributes to the establishment of the central-to-peripheral gradient in ganglion cell destiny.

Another set of interactions entirely consistent with the experimental results discussed above in the context of development of topographic order are those occurring between the terminals of retinal ganglion cells from the same eye within their targets. During normal development, ganglion cell axons from each eye establish a topographic map within the LGN that is not only orderly, but also reflects the heavy representation of central retina over peripheral retina. It may be that this feature of organization of the retinal projection actually arises as a consequence of interactions between axons of ganglion cells from the same eye within the target, as has been suggested previously (Stone et al., 1982). For example, progressively later arriving ganglion cell axons from peripheral retina might find most LGN territory already occupied by earlier-arriving axons from more central regions and therefore would compete for an ever-diminishing amount of target. Such a situation could cause a greater loss of ganglion cells from the peripheral than central retina, and this loss could be independent of the presence or absence of the other eye.

\section{Development of restricted terminal arbors after early monocular enucleation}

The major result of this study is our finding that individual retinogeniculate afferents can still develop a restricted terminal arbor in the absence of interactions with afferents from the other eye. These terminal arbors are very similar in size, shape, and complexity to terminal arbors found on normal retinogeniculate afferents. This raises the question of the nature of the interactions responsible for specifying the pattern of terminal arborization. It may be that some of the developmental mechanisms normally involved in restricting terminal arbors are present even in the absence of binocular interactions. One possibility is that in enucleated animals the terminal space available to each retinogeniculate afferent is somehow limited, perhaps due to the survival of excessive numbers of ganglion cells that would normally have died. Our finding here that the number of axons in the remaining optic nerve does not differ significantly from normal animals of the same age argues against this suggestion. However, the possibility remains that abnormal collateral branching at the optic chiasm or even more centrally could also result in limited terminal space within the LGN.

Another possibility is that cach afferent intrinsically may be capable only of arborizing within and innervating a limited amount of LGN territory during prenatal development. This possibility also seems unlikely to be a completely satisfactory explanation since the size of retinogeniculate terminal arbors during prenatal development can in fact be altered experimentally. For example, the removal of one eye later, at E44, after afferents from both eyes have innervated the LGN, causes some afferents from the remaining eye to expand into adjacent vacated territory and form an arbor that covers an area larger than normal (Sretavan et al., 1985). Thus, since under some circumstances, retinal afferents can in fact expand their terminal arbor, it seems much more reasonable to suppose that in the case of early enucleations, the afferents are actually restricted by extrinsically imposed factors.

Normal developmental mechanisms may in fact be responsible for producing, in enucleated animals, the remarkable arrangement of axon terminal arbors into tiers reminiscent of normal layers. If so, while effects such as crowding and intrinsic factors could conceivably account for the existence of restricted terminal arbors, they are certainly not sufficient to account for the tiers, and additional explanations are required. One such explanation derives from the observations that in the LGN of many mammals, afferents of different functional classes, such as ON-center or OFF-center ganglion cells, are segregated within separate layers (primate: Schiller and Malpeli, 1978; mink: LeVay and McConnell, 1982; ferrets: Stryker and Zahs, 1983). Recent evidence suggests that even in the cat, ON and OFF ganglion cell axons are segregated to some degree from the top to the bottom of a single layer (Bowling, 1984). Perhaps as a consequence of the early enucleation, ON and OFF afferents from the same eye, or some other functionally distinct classes, are now totally segregated into separate tiers. In theory, it should be possible to prove this by determining the functional identity of retinal ganglion cells that project to each tier by allowing enucleated animals to live until they are old enough to be studied physiologically. Such experiments are now in progress (e.g., see Sretavan et al., 1985). In this regard, it is worth speculating that had animals survived into postnatal life, separate cellular layers might have formed within the LGN, reflecting the tier-like arrangement of afferent input.

Another equally likely explanation derives from the fact that in normal animals, alternate layers such as layers $A$ and $A 1$ received input from the nasal retina of the contralateral eye or from the temporal retina of the ipsilateral eye (Sanderson, 1971; Stone, 1966; Stone and Fukuda, 1974). It is conceivable that the adjacent tiers seen in enucleated animals represent the separate projections from the nasal and temporal portions of the remaining retina. This unusual projection pattern could arise as a result of an abnormal decussation pattern at the chiasm. In the early-enucleation animals, one eye was removed before optic axons reach the optic chiasm. Consequently, the pattern of decussation could be highly abnormal and the normal partition of axons from nasal and temporal retina into the contralateral and ipsilateral tracts respectively might be perturbed. This type of decussation error is in fact known to exist in the neonatal cat's visual system, where a small projection from nasal retina into the ipsilateral tract has been found (Jacobs et al., 1984), but its magnitude during prenatal development is not known. It is quite possible that such mistakes at the chiasm are much more frequent in our monocularly enucleated animals and are also preserved and not eliminated. As a result, axons from all parts of the retina may be found together within each optic tract. Howcver, a rccent study of the effects of early enucleation on the retinofugal projection in the mouse (Godement, 1984) suggests that, at least for the ipsilateral projection, the decussation pattern is relatively normal.

In nature, abnormal decussation patterns at the optic chiasm exist in albino and pigment-deficient animals such as the Siamese cat. As a result of an error at the chiasm, the contralateral projection in these animals arises not only from the nasal retina, but also from adjacent parts of the temporal retina (Cooper and Pettigrew, 1979; Guillery, 1969; Shatz, 1979; Stone et al., 1978). It is now known that this decussation error occurs during the initial outgrowth of retinal afferents (Kliot and Shatz, 1985; Shatz and Kliot, 1982). Within the LGN of Siamese cats, afferent terminals from nasal and temporal retina project to separate but adjacent layers. By analogy, the adjacent tiers found in our monocularly enucleated animals could also represent terminal arbors from the nasal and temporal portions of the remaining retina. This can be proven by means of retrograde labeling of ganglion cells in enucleated animals-experiments that are also currently in progress.

In conclusion, the results of this study demonstrate that many normal features of the retinogeniculate projection can develop in the absence of binocular interactions. This by no means implies that binocular interactions are not important in the development of eye-specific layers of input in the normal animal. 
However, it serves to emphasize that axons do not interact with each other only on the basis of a difference in their eye of origin. Instead, they may interact with each other to produce layers because they are different from each other in other ways, just as retinal axons from the same eye may be different and, under the right experimental conditions, may sort out from each other into tiers. If so, then during development, what determines the final position, size, and shape of a retinal ganglion cell axon arbor within the LGN need not only be eye of origin, but also retinal site of origin (e.g., nasal versus temporal), functional identity, and other factors that distinguish retinal ganglion cells within a single retina from each other. Ganglion cells even within the same retina could be distinguished by differences in their pattern of activity in much the same way as has been proposed for axons from the two eyes in the development of ocular dominance columns in the cat (Stryker, 1981; Stryker and Harris, 1986; Stryker and Strickland, 1984) and in the development of ocular dominance stripes in the experimental retinotectal projection in amphibia and fish (Boss and Schmidt, 1985; Constantine-Paton and Reh, 1983; Meyer, 1982). This proposal is consistent with the finding that functional connections exist between retinal ganglion cells and LGN neurons throughout the prenatal period of the cat's fetal development under study here (Shatz and Kirkwood, 1984). It is also consistent with the observation that monocular blockade of activity by TTX during nconatal life in kittens produces LGN neurons that receive an abnormal mixture of functional properties from ganglion cells of the treated eye (Archer et al., 1982). Whatever the underlying mechanism, the results of our study underscore the importance of considering the interactions that may occur between the ganglion cells of one eye, as well as those occurring between both eyes, in describing the events associated with the normal development of this system.

\section{References}

Adams, J. C. (1981) Heavy metal intensification of DAB-based HRP reaction product. J. Histochem. Cytochem. 29: 775.

Archer, S. M., M. W. Dubin, and L. A. Stark (1982) Abnormal development of kitten retino-geniculate connectivity in the absence of action potentials. Science 217: 743-745.

Boss, V. C., and J. T. Schmidt (1985) Activity and the formation of ocular dominance patches in dually innervated tectum of goldfish. J. Neurosci. 4: 2891-2905.

Bowling, D. B. (1984) Differences in the timing and sensitivity of responses from cells across single layers of the lateral geniculate nucleus in the cat. Soc. Neurosci. Abstr. 10: 296.

Bunt, S. D., R. D. Lund, and P. W. Land (1983) Prenatal development of the optic projection in albino and hooded rats. Dev. Brain Res. 6 : 149-168.

Calvacante, L. A., and C. E. Rocha-Miranda (1978) Postnatal development of retinogeniculate, retinopretectal and retinotectal projections in the opossum. Brain Res. 146: 231-248.

Card-Linden, D., R. W. Guillery, and J. Cucchiaro (1981) The dorsal lateral geniculate nucleus of the normal ferret and its postnatal development. J. Comp. Neurol. 203: 189-211.

Chalupa, L. M., and R. W. Williams (1984) Organization of the cat's lateral geniculate nucleus following interruption of prenatal binocular competition. Hum. Neurobiol. 3: 103-107.

Chalupa, L. M., R. W. Williams, and Z. Henderson (1984) Binocular interaction in the fetal cat regulates the size of the ganglion cell population. Neuroscience 12: 1139-1146.

Constantine-Paton, M., and T. Reh (1983) Eye specific stripes in the tectal lobes of three-eyed frogs are dependent on neural activity. Soc. Neurosci. Abstr. 9: 760.

Cooper, M. L., and J. E. Pettigrew (1979) The retinothalamic pathways in Siamese cats. J. Comp. Neurol. 187: 313-348.

Crespo, D., D. D. M. O'Leary, and W. M. Cowan (1984) Reduction of optic nerve axons during the postnatal development of the albino rat. Soc. Neurosci. Abstr. 10: 464 .

Ferreira-Berrutti, P. (1951) Experimental deflection of the course of optic nerve in the chick embryo. Proc. Soc. Exp. Biol. Med. 71: 302303.

Frost, D. O., K. F. So, and G. E. Schneider (1979) Postnatal development of retinal projections in Syrian hamsters: A study using autoradiographic and anterograde degeneration techniques. Neuroscience 4: 1649-1677.

Godement, P. (1984) Development of retinal projections in the mouse. In Development of Visual Pathways in Mammals, J. Stone, B. Dreher, and D. H. Rappaport, eds., pp. 127-143, Alan R. Liss, New York.

Guillery, R. W. (1969) An abnormal retinogeniculate projection in Siamese cats. Brain Res. 14: 739-741.

Insausti, R., C. Blakemore, and W. M. Cowan (1984) Ganglion cell death during development of ipsilateral retino-collicular projection in golden hamster. Nature 308: 362-365.

Jacobs, D. S., V. H. Perry, and M. J. Hawken (1984) The postnatal reduction of the uncrossed projection from the nasal retina in the cat. J. Neurosci. 4: 2425-2433.

Kliot, M. and C. J. Shatz (1982) Genesis of different retinal ganglion cell types in the cat. Soc. Neurosci. Abstr. 8: 815.

Kliot, M., and C. J. Shatz (1985) Abnormal development of the retinogeniculate projection in Siamese cats. J. Neurosci. 5: 2641-2653.

Lam, K., J. Sefton, and M. R. Bennett (1982) Loss of axons from the optic nerve of the rat during early postnatal development. Dev. Brain Res. 3: 487-491.

LeVay, S., and S. K. McConnell (1982) On and Off layers in the lateral geniculate nucleus of the mink. Nature 300: 350-351.

Linden, R., and V. H. Perry (1982) Ganglion cell death within the developing retina: A regulatory role for retinal dendrites? Neuroscience 7: 2813-2827.

Meyer, R. L. (1982) Tetrodotoxin blocks the formation of ocular dominance columns in goldfish. Science 218: 589-591.

$\mathrm{Ng}, \mathrm{A}$, and J. Stone (1982) The optic nerve of the cat: Appearance and loss of axons during normal development. Dev. Brain Res. 5: 263-271.

O'Leary, D. D. M., J. W. Fawcett, and W. M. Cowan (1984) Elimination of topographical errors in the retinocollicular projection by ganglion cell death. Soc. Neurosci. Abstr. 10: 464.

Perry, V.H., and R. Linden (1982) Evidence for dendritic competition in the developing retina. Nature 297: 683-685.

Rakic, P. (1977) Prenatal development of the visual system in rhesus monkey. Phil. Trans. R. Soc. London [Biol.] 278: 245-260.

Rakic, P. (1981) Development of visual centers in the primate brain depends on binocular competition beforc birth. Science 214:928.

Rakic, P., and K. P. Riley (1983a) Overproduction and elimination of retinal axons in the fetal rhesus monkey. Science 219: 1441-1444.

Rakic, P., and K. Riley (1983b) Regulation of axon number in primate optic nerve by prenatal binocular competition. Nature 305: 135-137.

Sanderson, K. J. (1971) The projection of the visual field to the lateral geniculate and medial interlaminar nuclei in the cat. J. Comp. Neurol. 143: $101-118$.

Sanderson, K. J., P. G. Dixon, and L. P. Pearson (1982) Postnatal development of retinal projections in the brushtailed possum, Trichosurus vulpecula. Dev. Brain Res. 5: 161-180.

Schiller, P. H., and J. G. Malpeli (1978) Functional specificity of lateral geniculate nucleus laminae of the Rhesus monkey. J. Neurophysiol. 41: 788-797.

Sengelaub, D. R., and B. L. Finlay (1982) Cell death in the mammalian visual system during normal development: I. Retinal ganglion cells. J. Comp. Neurol. 204: 311-317.

Shatz, C. J. (1979) Abnormal connections in the visual system of Siamese cats. Soc. Neurosci. Symp. 4: 121-141.

Shatz, C. J. (1983) The prenatal development of the cat's retinogeniculate pathway. J. Neurosci. 3: 482-499.

Shatz, C. J., and P. Kirkwood (1984) Prenatal development of functional connections in the cat's retinogeniculate pathway. J. Neurosci. 4: 1378-1397.

Shatz, C. J., and M. Kliot (1982) Prenatal misrouting of the retinogeniculate pathway in Siamese cats. Nature 300:525-529.

Shatz, C. J., and D. W. Sretavan (1986) Interactions between retinal ganglion cells during the development of the mammalian visual system. Annu. Rev. Neurosci. 9: 171-207.

So, K.-F., G. E. Schneider, and D. O. Frost (1978) Postnatal development of retinal projections to the lateral geniculate body in Syrian hamsters. Brain Res. 142: 343-352.

So, K.-F., H. H. Woo, and L. S. Jen (1984) The normal and abnormal 
postnatal development of retinogeniculate projections in golden hamsters: An anterograde horseradish peroxidase tracing study. Dev. Brain Res. 12: 191-205.

Sretavan, D. W., and C. J. Shatz (1984) Prenatal development of individual retinogeniculate axons during the period of segregation. Nature 308: 845-848.

Sretavan, D. W., and C. J. Shatz (1986) Prenatal development of retinal ganglion cell axons: Segregation into eye-specific layers within the cat's lateral geniculate nucleus. J. Neurosci. 6: 234-251.

Sretavan, D. W., M. Kliot, and C. J. Shatz (1984) Observations on the development of the cat's retinogeniculate pathway in the absence of binocular interactions. Soc. Neurosci. Abstr. 10:670.

Sretavan, D. W., P. E. Garraghty, M. Sur, and C. J. Shatz (1985) Development of retinogeniculate axon arbors following prenatal unilateral enucleation. Soc. Neurosci. Abstr. 11: 805.

Stone, J. (1965) A quantitative analysis of the distribution of ganglion cells in the cat's retina. J. Comp. Neurol. 124: 337-352.

Stone, J. (1966) The nasotemporal division of the cat's retina. J. Comp. Neurol. 126: 585-600.

Stone, J. (1978) The number and distribution of ganglion cells in the cat's retina. J. Comp. Neurol. 180: 735-772.

Stone, J., and Y. Fukuda (1974) The nasotemporal division of the cat's retina re-examined in terms of $Y-, X$ - and W-cells. J. Comp. Ncurol. 155: 377-394.

Stone, J., J. Campion, and J. Leicester (1978) Nasotemporal division of retina in the Siamese cat. J. Comp. Neurol. 180: 783-798.
Stone, J., D. H. Rapaport, R. W. Williams, and L. Chalupa (1982) Uniformity of cell distribution in the ganglion cell layer of prenatal cat retina: Implications for mechanisms of retinal development. Dev. Brain Res. 2: 231-242.

Stryker, M. P. (1981) Late segregation of the geniculate afferents to the cat's visual cortex after recovery from binocular impulse blockade. Soc. Neurosci. Abstr. 7:842.

Stryker, M. P., and W. Harris (1986) Binocular impulse blockade prevents the formation of ocular dominance columns in cat visual cortex. J. Neurosci. (in press).

Stryker, M. P., and S. L. Strickland (1984) Physiological segregation of ocular dominance columns depends on the pattern of afferent electrical activity. Invest. Ophthalmol. Vis. Sci. (Suppl.) 25: 278.

Stryker, M. P., and K. Zahs (1983) On and Off sublaminae in the lateral geniculate nucleus of the ferret. J. Neurosci. 3: 1943-1951.

Williams, R. W., M. J. Bastiani, and L. M. Chalupa (1983a) Addition and attrition of axons within the optic nerve during fetal development: Appearance of growth cones and necrotic axons. Invest. Ophthalmol. Vis. Sci. (Suppl.) 24: 8.

Williams, R. W., M. Bastiani, and L. M. Chalupa (1983b) Loss of axons in the cat optic nerve following fetal unilateral enucleation: An electron microscopic analysis. J. Neurosci. 3: 133-144.

Williams, R. W., M. Bastiani, B. Lia, and L. M. Chalupa (1986) Growth cones, dying axons, and developmental fluctuations in the fiber population of the cat's optic nerve. J. Comp. Neurol. (in press). 